\title{
Effects of anesthetic induction in patients with diastolic dysfunction
}

\section{Les effets de l'induction de l'anesthésie chez les patients souffrant de dysfonction diastolique}

\author{
Pierre Couture, MD · André Y. Denault, MD - Yanfen Shi, MD · \\ Alain Deschamps, MD, PhD · Mariève Cossette, Msc • \\ Michel Pellerin, MD · Jean-Claude Tardif, MD
}

Received: 9 September 2008/Revised: 8 January 2009/ Accepted: 19 January 2009/Published online: 2 April 2009

(C) Canadian Anesthesiologists' Society 2009

\begin{abstract}
Purpose To evaluate the effects of anesthetic induction on bi-ventricular function in patients with known preoperative left ventricular $(L V)$ diastolic dysfunction undergoing coronary artery bypass grafting surgery $(C A B G)$.

Methods Fifty patients with diastolic dysfunction undergoing $C A B G$ were studied. Preoperative transthoracic echocardiographic (TTE) examination was performed on the day before surgery and transesophageal echocardiography (TEE) assessment was undertaken after induction of anesthesia with sufentanil, midazolam,
\end{abstract}

Presented in part at the Canadian Anesthesiologists' Society Annual Meeting, Toronto, ON, Canada, June 16-20, 2006.

This article is accompanied by an editorial. Please see Can J Anesth 2009; 56: 5 .

P. Couture, MD $(\bowtie) \cdot$ A. Y. Denault, MD .

A. Deschamps, MD, PhD

Department of Anesthesiology, Montreal Heart Institute and Université de Montréal, 5000 Belanger Street, Montreal, QC H1T1C8, Canada

e-mail: pierre.couture@icm-mhi.org

\section{Pellerin, MD}

Department of Cardiac Surgery, Montreal Heart Institute and Université de Montréal, Montreal, QC, Canada

J.-C. Tardif, MD

Department of Medicine, Montreal Heart Institute and Université de Montréal, Montreal, QC, Canada

Y. Shi, MD

The Research Center, Montreal Heart Institute and Universite de Montréal, Montreal, QC, Canada

M. Cossette, Msc

Montreal Heart Institute Coordinating Center, Montreal, QC, Canada isoflurane, and pancuronium. Mean arterial pressure $(M A P)$ and heart rate $(H R)$ were recorded. The diameters of the left atrium (LA) and right atrium (RA) and right ventricular $(R V)$ end-diastolic area (EDA), end-systolic area (ESA) and fractional area change (FAC) were obtained from the apical 4-chamber view. The LV EDA, LV ESA and LV FAC were measured from a transgastric midpapillary view. Pulsed wave Doppler of the transmitral flow (TMF) and transtricuspid flow (TTF), pulmonary venous flow (PVF) and hepatic venous flow (HVF) were measured. Mitral (Em, Am) and tricuspid (Et, At) annulus velocities were assessed by tissue Doppler imaging (TDI). Assessment of diastolic dysfunction was graded from normal to severe using a validated score.

Results Following induction of anesthesia, HR decreased $\left(66 \pm 12\right.$ vs $55 \pm 9$ beats $\left.\cdot \mathrm{min}^{-1}, P<0.0001\right)$ while MAP remained unchanged $(86.1 \pm 9.0$ vs $85.6 \pm 26.5 \mathrm{mmHg}$, $P=0.94)$. The diameters of the $L A, R A$ and $R V$ chambers increased, and these increases were associated with opposite changes in LV dimensions. The RV FAC decreased, but the $L V$ FAC remained unchanged. While most Doppler velocities decreased $(P<0.05)$, a greater reduction in the atrial components of the TMF, TTF and TDI ratios was observed. The LV diastolic function score improved after induction of anesthesia $(100 \%$ of patients with a score $\geq=3$ preinduction compared to $58 \%$ of patients with a score $\geq 3$ postinduction; $P=0.0004$ ).

Conclusion In patients with left ventricular diastolic dysfunction, cardiac dimensions and bi-ventricular filling patterns are significantly altered after induction of general anesthesia. These changes can be explained to some extent by a reduction in venous return with general anesthesia, reduced atrial contractility, and the effect of positive pressure ventilation. Although the $L V$ diastolic function score improved after induction of anesthesia, it is difficult 
to dissociate this effect from that of altered loading conditions.

\section{Résumé}

Objectif Évaluer les effets de l'induction anesthésique sur la fonction biventriculaire des patients présentant une dysfonction diastolique ventriculaire gauche (VG) préopératoire connue et subissant un pontage aortocoronarien $(P A C)$.

Méthode Cinquante patients souffrant de dysfonction diastolique et subissant un PAC ont été évalués. Une échocardiographie transthoracique (TTE) a été réalisée la veille de la chirurgie et une échocardiographie transoesophagienne (TEE) a été entreprise une fois l'anesthésie induite à l'aide de sufentanil, midazolam, isoflurane et pancuronium. La tension artérielle moyenne (TAM) et la fréquence cardiaque (FC) ont été enregistrées. Les diamètres de l'oreillette gauche $(O G)$ et de l'oreillette droite $(O D)$ et la surface télédiastolique (STD) du ventricule droit (VD), la surface télésystolique (STS) et la fraction de raccourcissement de surface (FRS) ont été obtenus avec une coupe apicale 4 chambres. Les STDVG, STS VG, et FRS VG ont été mesurées avec une coupe transgastrique mid-papillaire. Un Doppler pulsé des débits transmitral (TMF) et transtricuspide (TTF), les débits sanguins veineux pulmonaire (PVF) et hépatiques (HVF) ont étémesurés. Les vélocités de l'anneau mitral (ondes Em et Am) et tricuspide (ondes Et et At) ont été évaluées par Doppler tissulaire (TDI). L'évaluation de la dysfonction diastolique a été classée de normale à grave à l'aide d'une échelle validée. Résultats À la suite de l'induction de l'anesthésie, la FC a diminué (66 \pm 12 vs $55 \pm 9$ battements. $\left.\mathrm{min}^{-1}, P<0,0001\right)$ alors que la TAM n'a pas montréde changements $(86,1 \pm 9,0$ vs 85,6 $\pm 26,5 \mathrm{mmHg}, P=0,94)$. Les diamètres de l'OG, l'OD et des chambres du VD ont augmenté, et ces augmentations étaient associées avec des changements inverses dans les dimensions du VG. La FRS du VD a diminué, mais la FRS du VG n'a pas changé. Alors que la majorité des vélocités Doppler ont diminué $(P<0,05)$, une plus grande réduction a été observée dans les composantes auriculaires des rapports TMF, TTF et TDI. Le score de fonction diastolique du VG s'est amelioréaprès l'induction de l'anesthésie (100\% des patients présentant un score $\geq=3$ avant l'induction par rapport à $58 \%$ des patients présentant un score $\geq 3$ après l'induction; $P=0,0004)$.

Conclusion Chez les patients présentant une dysfonction diastolique $d u$ ventricule gauche, les dimensions cardiaques et les modèles de remplissage sont considérablement altérés après l'induction d'une anesthésie générale. Ces changements peuvent s'expliquer dans une certaine mesure par une réduction du retour veineux avec une anesthésie générale, une contractilité auriculaire réduite, et l'effet de la ventilation à pression positive. Bien que le score de la fonction diastolique du VG se soit amélioré après l'induction de l'anesthésie, il est difficile de dissocier cet effet de celui de conditions de charge altérées.

The clinical impact of preoperative left ventricular $(\mathrm{LV})^{1-5}$ and right ventricular $(\mathrm{RV})^{4,6}$ diastolic dysfunction on perioperative morbidity and mortality is increasingly recognized. The presence of severe LV diastolic dysfunction is associated with hemodynamic instability after cardiopulmonary bypass (CPB) and has been correlated with postoperative cardiac events $1 \mathrm{yr}$ after coronary artery bypass graft $(\mathrm{CABG})$ surgery. ${ }^{3}$ This is clinically important because the prevalence of $\mathrm{LV}$ diastolic dysfunction has been estimated to be $30 \%$ in elderly and hypertensive patients undergoing cardiac surgery. ${ }^{1}$ Furthermore, we have previously observed that both LV and RV diastolic abnormalities were the most common echocardiographic findings in hemodynamically unstable patients after cardiac surgery. ${ }^{7}$ It is therefore relevant to evaluate diastolic function before, during, and after cardiac surgery.

LV and RV diastolic function are usually assessed when the patient is anesthetized in the operating room before cardiac surgery. The effect of induction of general anesthesia on the LV and RV filling patterns in patients with known diastolic dysfunction has not been well studied. Accordingly, the purpose of this clinical investigation was to determine the effect of general anesthesia on cardiac dimensions and bi-ventricular diastolic filling patterns in patients with pre-existing diastolic dysfunction undergoing CABG. We hypothesized that induction of anesthesia, through altered loading conditions, altered inotropy, and positive pressure ventilation in patients with compromised left ventricular diastolic function, can alter cardiac dimensions and modify systolic and diastolic function.

\section{Methods}

Following approval of the study protocol by the Research and Ethics Committees of the Montreal Heart Institute and after obtaining individual written informed consent, we screened consecutive patients undergoing $C A B G$ surgery under CPB for LV diastolic dysfunction, as determined by preoperative transthoracic echocardiographic examination performed by an expert cardiologist on the day before surgery. The study was part of a trial examining the efficacy of intravenous milrinone ${ }^{8,9}$; however, in consideration of this analysis, neither the study drug nor the placebo was administered before the post-induction TEE examination was performed. Patients with mitral or aortic valve disease, those with atrial fibrillation or a pacemaker, and those with 
any contraindication to transesophageal echocardiography (TEE) were excluded. Preoperative data included demographic information, presence of co-morbid conditions, concurrent medications, and the results of basic laboratory screening tests.

\section{Perioperative management}

Following induction of anesthesia and tracheal intubation, a radial artery catheter, a pulmonary artery catheter, and a TEE probe (Sonos 5500, Hewlett-Packard, Andover, MA, USA) were inserted. The anesthetic drugs included sufentanil $\left(1 \mu \mathrm{g} \cdot \mathrm{kg}^{-1}\right.$ iv for induction and $1 \mu \mathrm{g} \cdot \mathrm{kg}^{-1} \cdot \mathrm{h}^{-1}$ until the end of surgery), midazolam $\left(0.04 \mathrm{mg} \cdot \mathrm{kg}^{-1}\right.$ iv during induction followed by $0.04 \mathrm{mg} \cdot \mathrm{kg}^{-1} \cdot \mathrm{h}^{-1}$ ), isoflurane (endtidal concentration between $0.5 \%$ and $1.0 \%$ ), and pancuronium. Hypotension-defined as mean arterial pressure (MAP) $<60 \mathrm{mmHg}$ or a decrease in MAP of $>20 \%$ compared to the pre-anesthesia value before or during $\mathrm{CPB}-$ was treated with phenylephrine infusion at the discretion of the attending anesthesiologist caring for the patient. Each patient received $500-750 \mathrm{~mL}$ of isotonic crystalloid (Ringer's lactate) during the anesthetic induction sequence.

\section{Hemodynamic measurements}

Hemodynamic measurements included the heart rate and blood pressure. Data obtained from the pulmonary artery catheter were not included in this study, because they were not available in the preoperative period when the transthoracic echocardiographic examination was performed. The heart rate and mean arterial blood pressure (MAP) were taken during stable hemodynamic conditions, i.e., after the insertion of the Swan Ganz catheter and before surgical incision.

\section{Echocardiographic measurements}

A standard transthoracic echocardiographic examination was undertaken the day before surgery, and a TEE examination was undertaken after the anesthetic induction was performed. These assessments and measurements were performed in a stable hemodynamic setting at the same time as the heart rate and the MAP were recorded. Completed in less than ten minutes, the TEE examinations and measurements included assessments of the LV and RV dimensions, the regional and global function and the mitral, aortic, and tricuspid valve function using a colour flow Doppler examination.

To assess LV and RV systolic function and dimensions, LV end-diastolic area (EDA), end-systolic area (ESA), and fractional area change (FAC) were measured from the transgastric mid-papillary view. The diameter of the left atrium (LA), the right atrium (RA), the RV at end-diastole, the RV ESA, RV EDA, and RV FAC were obtained from the mid-esophageal four-chamber view using published guidelines on two-dimensional quantification. ${ }^{10}$

To assess LV and RV diastolic function, pulsed wave (PW) Doppler was used to evaluate transmitral flow (TMF) and transtricuspid inflow (TTF). Peak early (E) and peak late (A) diastolic flow velocities were measured. Pulmonary venous flow (PVF) and hepatic venous flow (HVF) were also evaluated using PW Doppler, and peak systolic (S), diastolic (D), and atrial reversal (AR) flow velocities were measured.

Mitral annulus velocities (Em and Am) were measured at the lateral or anterior annulus by tissue Doppler imaging (TDI); the signal with the best definition and with the higher Em was chosen. Tricuspid annulus velocities (Et and At) were also determined by TDI using a deep transgastric RV long axis view with right side rotation, as previously described. ${ }^{4}$

The classification of LV diastolic function was based on a modification of the algorithm described by Khouri et al. ${ }^{11}$ that we previously validated ${ }^{4,12}$ (Fig. 1). LV diastolic function was graded ranging from normal to severe dysfunction using the following scores: grade 1 (normal: TMF flow $\mathrm{E} / \mathrm{A}>1, \mathrm{PVF} \mathrm{S} / \mathrm{D}>1, \mathrm{Em} / \mathrm{Am}>1)$, grade $2(\mathrm{E} / \mathrm{A}>1$, $\mathrm{S} / \mathrm{D}>1, \mathrm{Em} / \mathrm{Am}<1)$, grade $3(\mathrm{E} / \mathrm{A}<1, \mathrm{~S} / \mathrm{D}>1, \mathrm{Em} / \mathrm{Am}$ $<1)$, grade $4(\mathrm{E} / \mathrm{A}>1, \mathrm{~S} / \mathrm{D}<1, \mathrm{Em} / \mathrm{Am}<1)$, and grade 5 $(\mathrm{E} / \mathrm{A}>2, \mathrm{~S} / \mathrm{D}<1, \mathrm{Em} / \mathrm{Am}<1)$.

Assessment of RV diastolic function was performed using TTF, HVF, ${ }^{13}$ and TDI of the tricuspid annulus (Fig. 2). A normal HVF was defined as a ratio of systolic to diastolic velocities $>1$, with the AR velocity less than half of the maximum systolic wave velocity. ${ }^{14}$ Moderate to severe RV diastolic dysfunction was considered present if the systolic waveform was reduced or inverted on the Doppler HVF in the absence of severe tricuspid regurgitation. RV diastolic function was graded as follows: grade 1 (normal: TTF E/A >1, HVF S/D >1, Et/At $>1$ ), grade 2 (TTF E/A $<1$, or reversed $\mathrm{Ar}>50 \%$ of $\mathrm{S}$ wave measured on $\mathrm{HVF}$, or Et $<$ At when both E/A and S/D $>1$ ), grade 3 (TTF $\mathrm{E} / \mathrm{A}>1, \mathrm{~S} / \mathrm{D}<1, \mathrm{Et} / \mathrm{At}<1$ ), and grade 4 (S wave reversal on $\mathrm{HVF}$, irrespective of the E/A and S/D ratio), as previously described. ${ }^{4}$ All the echocardiographic data were recorded on a magnetic optical disk for off-line viewing. The echocardiographic images were reviewed off-line by two independent observers who were blinded to the patients' data. Our inter-observer variability for the assessment of systolic and diastolic function has been previously published. ${ }^{1,4,7,8},{ }^{15,16}$ The coefficients of variation were $3.4 \% \pm 1.4 \%$ and $4.4 \% \pm 1.9 \%$ for the left and right ventricular end-diastolic areas, respectively. ${ }^{8}$ For PW velocity and TDI velocity, the coefficients of variation were $5.4 \% \pm 2.6 \%$ and $2.6 \% \pm 1.3 \%$, respectively. ${ }^{8}$ The 


\section{LEFT VENTRICULAR DIASTOLIC DYSFUNCTION (DD)}

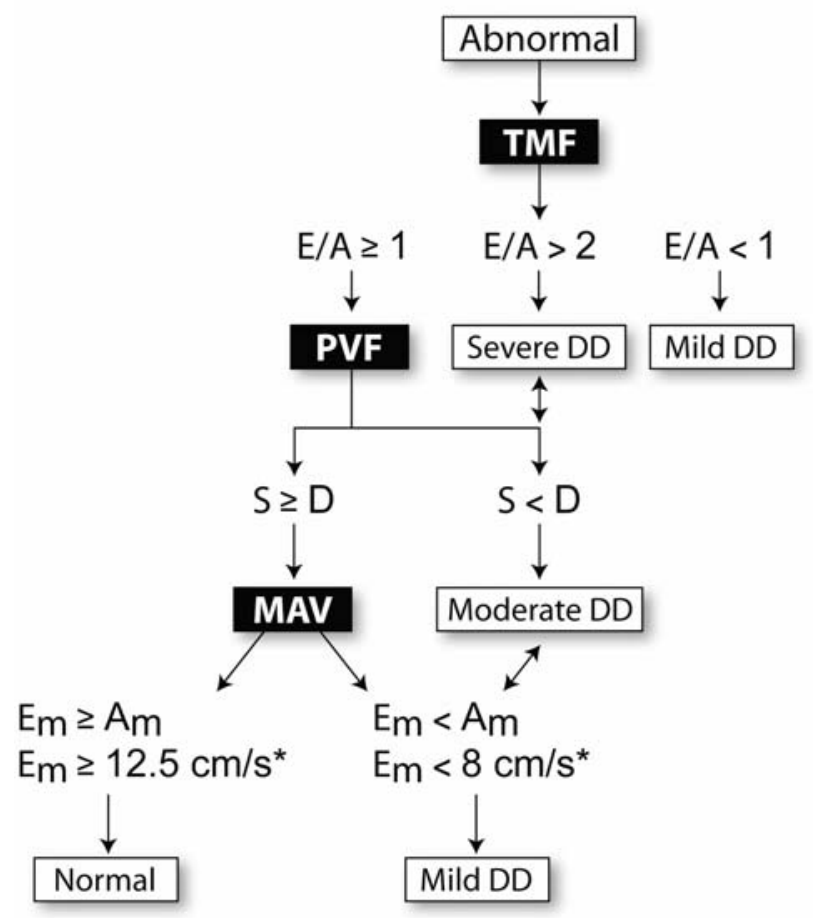

Fig. 1 Algorithm used in the diagnosis and classification of left ventricular diastolic dysfunction. The diastolic dysfunction is classified using pulsed-wave Doppler of the transmitral (TMF), pulmonary venous flow (PVF) and tissue Doppler examination of mitral annular velocity (MAV). $\mathrm{A}=$ atrial filling $\mathrm{A}$-wave velocity of the TMF; $\mathrm{Am}=$ late mitral annular velocity; $\mathrm{D}=$ diastolic component of the PVF; $\mathrm{E}=$ early filling of the TMF; Em = early mitral annular velocity; $\mathrm{S}=$ systolic component of the PVF. Left ventricular diastolic function was graded on a five scale score ranging from normal to severe diastolic dysfunction. LV diastolic function was graded as: grade 1 (normal) (TMF E/A $>1, \mathrm{PVF} \mathrm{S/D}>1, \mathrm{Em} / \mathrm{Am}>1$ ), grade $2(\mathrm{E} / \mathrm{A}>1, \mathrm{~S} / \mathrm{D}>1, \mathrm{Em} / \mathrm{Am}<1)$, grade $3(\mathrm{E} / \mathrm{A}<1, \mathrm{~S} / \mathrm{D}>1, \mathrm{Em} /$ $\mathrm{Am}<1)$, grade $4(\mathrm{E} / \mathrm{A}>1, \mathrm{~S} / \mathrm{D}<1, \mathrm{Em} / \mathrm{Am}<1)$, and grade $5(\mathrm{E} / \mathrm{A}>2$, $\mathrm{S} / \mathrm{D}<1, \mathrm{Em} / \mathrm{Am}<1$ ) (With permission of The Canadian Journal of Anesthesia)

use of the LVDD and RVDD criteria were previously validated using Cohen's kappa values. ${ }^{4}$ The kappa values were 0.77 and 0.82 for the LVDD and RVDD evaluation, respectively. ${ }^{4}$

\section{Statistical methods}

Hemodynamic and echocardiographic variables are presented as mean $\pm \mathrm{SD}$. All comparisons involved assessment of preoperative vs post-induction values using paired Student's $t$ tests. Because of the uneven distribution of patients within the five-scale scores for assessment of left and right ventricular diastolic function, frequencies and percentages are presented and the non-parametric Wilcoxon signed-rank

\section{RIGHT VENTRICULAR DIASTOLIC DYSFUNCTION (DD)}

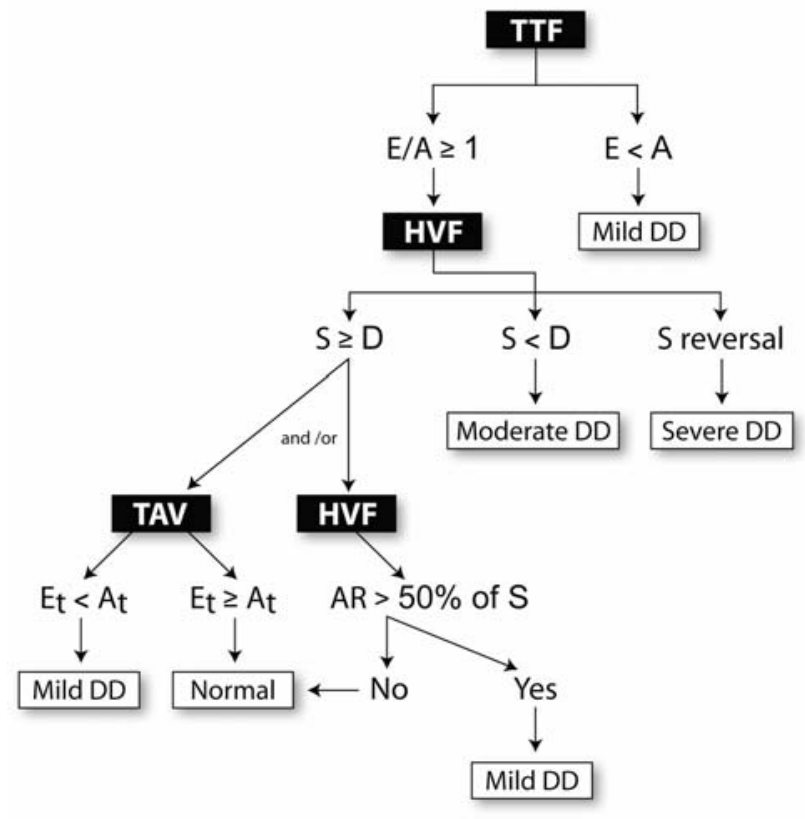

Fig. 2 Algorithm used in the diagnosis and classification of right ventricular diastolic dysfunction. Diastolic function is classified by pulsed-wave Doppler of the transtricuspid flow (TTF), hepatic venous flow (HVF), and tissue Doppler imaging of the tricuspid annulus or tricuspid annular velocity (TAV). A = atrial component of the TTF; $\mathrm{Ar}=$ reversed atrial flow of the HFV; $\mathrm{Ar}=$ atrial component of the TAV; $\mathrm{D}=$ diastolic component of the HVF; $\mathrm{E}=$ early filling of the TTF; Et = early component of the TAV; $\mathrm{S}=$ systolic component of the HVF. Right ventricular diastolic dysfunction score was classified as: grade 1 (normal) (TTF E/A >1, HVF S/D >1, Et/At $>1$ ), grade 2 (E/A $<1$, or reversed $\mathrm{Ar}>50 \%$ of $\mathrm{S}$ wave measured on $\mathrm{HVF}$, or $\mathrm{Et}$ $<$ At when both E/A and S/D $>1)$, grade $3(\mathrm{E} / \mathrm{A}>1$, S/D $<1$, Et/At $<1$ ), and grade 4 (S wave reversal on HVF, irrespective of the E/A and S/D ratio) (With permission of the Canadian Journal of Anesthesia)

test was used to compare the left and right ventricular diastolic functions in response to anesthetic induction. All analyses were performed with SAS version 8.2 (SAS Institute Inc., Cary, NC, USA) and conducted at the 0.05 significance level. A posteriori power analysis of our study provides $80 \%$ power to detect an $8 \mathrm{~cm} / \mathrm{sec}$ difference in the TMF E velocities before and after the induction of anesthesia, assuming a standard deviation for the difference of $20 \mathrm{~cm} / \mathrm{sec}$ and using a two-sided significance level of 0.05 .

\section{Results}

Fifty of the 70 patients who were screened during the period from September 2002 to June 2004 met at least one of our criteria for preoperative LV diastolic dysfunction on the transthoracic echocardiographic examination performed the day before CABG. In one of the 50 patients (38 
Table 1 Patients characteristics and postoperative outcomes

\begin{tabular}{ll}
\hline Fractional area change (\%) (mean \pm SD) & $48.8 \pm 12.0$ \\
Parsonnet score (mean \pm SD) & $10.2 \pm 5.4$ \\
Creatinine (mmol/L) (mean \pm SD) & $86.8 \pm 20.9$ \\
Number of venous coronary bypass (mean \pm SD) & $2.2 \pm 1.0$ \\
Number of internal mammary artery & $1.1 \pm 0.4$ \\
$\quad$ bypass (mean \pm SD) & $169.8 \pm 38.6$ \\
Surgery duration (minutes) (mean \pm SD) & $73.1 \pm 22.4$ \\
Cardiopulmonary bypass time (minutes) & \\
$\quad$ (mean \pm SD) & $45.8 \pm 18.6$ \\
Aortic clamping time (hours) (mean \pm SD) & \\
Postoperative outcomes: & 17 \\
Atrial fibrillation (number of patients) & 2 \\
Ventricular tachycardia (number of patients) & 3 \\
Acute renal failure (number of patients) & 1 \\
Pulmonary edema (number of patients) & 3 \\
Pneumonia (number of patients) & $13.3 \pm 11.6$ \\
Intubation duration (hours) (mean \pm SD) & $3.0 \pm 5.0$ \\
Intensive care length of stay (days) (mean \pm SD) & $7.1 \pm 10.5$ \\
Hospital length of stay (days) (mean \pm SD) & 5 \\
Acute respiratory failure (number of patients) & 2 \\
Death (number of patients) & \\
\hline
\end{tabular}

men), TEE probe insertion was unsuccessful; in four patients, LV diastolic function could not be evaluated at the two time points (the day before surgery and after anesthesia induction), and in 13 patients, RV diastolic function could not be evaluated due to inadequate image quality. The mean patient age was $68.3 \pm 7.8 \mathrm{yr}$, the mean weight was $81.8 \pm 15.3 \mathrm{~kg}$, and the mean height was $167.4 \pm 9.2 \mathrm{~cm}$. Thirty-nine patients had hypertension, 22 had diabetes mellitus, 22 used an angiotensin converting enzyme inhibitor, 27 used calcium channel blockers, and 39 were receiving beta-adrenergic blocking agents. Other patient characteristics and outcomes are presented in Table 1.

Hemodynamic and electrocardiographic data

After general anesthesia, the HR decreased (66 $\pm 12 v s$ $55 \pm 9$ beats $\left.\min ^{-1}, P<0.0001\right)$ while the MAP remained stable $(86.1 \pm 9.0$ vs $85.6 \pm 26.5 \mathrm{mmHg}, P=0.94)$ when compared to preoperative values. Based on ST segment monitoring, there was no evidence of arrhythmia or myocardial ischemia. MAP was not an averaged value over the entire period of acquiring data, but was obtained in less than 5 min at a given point when TEE data acquisition began.

\section{Echocardiographic data}

Echocardiographic data are shown in Table 2. After induction of general anesthesia, the diameters of the LA and RA increased (LA: $4.0 \pm 0.4$ to $4.4 \pm 0.6, P=0.0025$ and RA:
Table 2 Echocardiographic variables

\begin{tabular}{|c|c|c|c|}
\hline & Preoperative & $\begin{array}{l}\text { After anesthetic } \\
\text { induction }\end{array}$ & $P$ value \\
\hline LA diameter $(\mathrm{cm})$ & $4.0 \pm 0.4$ & $4.4 \pm 0.6$ & $<0.01$ \\
\hline LV EDA $\left(\mathrm{cm}^{2}\right)$ & $22.7 \pm 6.9$ & $16.2 \pm 5.2$ & $<0.0001$ \\
\hline LV ESA $\left(\mathrm{cm}^{2}\right)$ & $12.3 \pm 6.1$ & $8.6 \pm 4.2$ & $<0.0001$ \\
\hline LV (FAC) $(\%)$ & $48.0 \pm 13.0$ & $49.0 \pm 12.0$ & 0.68 \\
\hline TMF E $(\mathrm{cm} / \mathrm{sec})$ & $68.3 \pm 17.0$ & $61.5 \pm 15.8$ & $<0.001$ \\
\hline TMF A $(\mathrm{cm} / \mathrm{sec})$ & $83.3 \pm 21.6$ & $55.5 \pm 18.5$ & $<0.0001$ \\
\hline TMF E/A ratio & $0.88 \pm 0.39$ & $1.36 \pm 1.28$ & 0.01 \\
\hline PVF S (cm/sec) & $50.1 \pm 12.3$ & $47.6 \pm 12.1$ & 0.48 \\
\hline PVF D (cm/sec) & $44.7 \pm 12.4$ & $34.3 \pm 10.8$ & $<0.0001$ \\
\hline PVF S/D ratio & $1.2 \pm 0.4$ & $1.5 \pm 0.4$ & $<0.01$ \\
\hline PVF Ar $(\mathrm{cm} / \mathrm{sec})$ & $29.6 \pm 5.0$ & $17.6 \pm 6.3$ & $<0.0001$ \\
\hline MAV Em $(\mathrm{cm} / \mathrm{sec})$ & $8.5 \pm 2.3$ & $7.0 \pm 1.5$ & $<0.001$ \\
\hline MAV Am $(\mathrm{cm} / \mathrm{sec})$ & $11.7 \pm 3.2$ & $8.8 \pm 2.1$ & $<0.0001$ \\
\hline MAV Em/Am ratio & $0.76 \pm 0.25$ & $0.84 \pm 0.28$ & $<0.05$ \\
\hline RA diameter $(\mathrm{cm})$ & $3.7 \pm 0.5$ & $4.7 \pm 0.8$ & $<0.0001$ \\
\hline RV EDA $\left(\mathrm{cm}^{2}\right)$ & $13.9 \pm 3.8$ & $15.6 \pm 3.5$ & 0.05 \\
\hline RV ESA $\left(\mathrm{cm}^{2}\right)$ & $6.9 \pm 2.3$ & $9.0 \pm 3.0$ & $<0.001$ \\
\hline RV FAC (\%) & $50.1 \pm 8.7$ & $42.6 \pm 13.6$ & $<0.01$ \\
\hline TTF E $(\mathrm{cm} / \mathrm{sec})$ & $47.2 \pm 9.8$ & $35.8 \pm 9.2$ & $<0.0001$ \\
\hline TTF A (cm/sec) & $46.5 \pm 12.6$ & $29.5 \pm 11.9$ & $<0.0001$ \\
\hline TTF E/A ratio & $1.06 \pm 0.24$ & $1.33 \pm 0.50$ & $<0.01$ \\
\hline HVF S $(\mathrm{cm} / \mathrm{sec})$ & $49.6 \pm 21.0$ & $22.3 \pm 8.5$ & $<0.0001$ \\
\hline HVF D $(\mathrm{cm} / \mathrm{sec})$ & $38.3 \pm 14.3$ & $15.1 \pm 6.9$ & $<0.0001$ \\
\hline HVF S/D ratio & $1.3 \pm 0.4$ & $1.6 \pm 0.5$ & $<0.01$ \\
\hline HVF $\operatorname{Ar}(\mathrm{cm} / \mathrm{sec})$ & $33.1 \pm 8.5$ & $13.0 \pm 8.2$ & $<0.0001$ \\
\hline TAV Et $(\mathrm{cm} / \mathrm{sec})$ & $9.3 \pm 2.7$ & $5.8 \pm 1.6$ & $<0.0001$ \\
\hline TAV At $(\mathrm{cm} / \mathrm{sec})$ & $14.9 \pm 3.8$ & $8.8 \pm 2.0$ & $<0.0001$ \\
\hline TAV Et/At ratio & $0.63 \pm 0.11$ & $0.68 \pm 0.23$ & 0.20 \\
\hline
\end{tabular}

$L A$ left atrium, $R A$ right atrium, $L V$ left ventricle, $R V$ right ventricle, $E D A$ end-diastolic area, ESA end-systolic area, $F A C$ fractional area change, $T M F E$ transmitral flow $\mathrm{E}$ wave, $T M F A$ transmitral flow A wave, $T M F E / A$ wave transmitral flow E/A wave ratio, $P V F S$ pulmonary venous flow systolic wave, $P V F D$ pulmonary venous flow diastolic wave, $P V F$ Ar pulmonary venous flow during atrial reversal, $P V F S / D$ pulmonary venous flow ratio of the S/D waves, $M A V E m$ tissue Doppler imaging measurement of the mitral annulus velocity $\mathrm{E}$ wave, TDI Am tissue Doppler imaging measurement of the mitral annulus velocity A wave, TDI Em/Am tissue Doppler imaging measurement of the Em/Am ratio, TTF $E$ transtricuspid flow $\mathrm{E}$ wave, $T T F$ A wave transtricuspid flow A wave, TTF E/A wave transtricuspid flow E/A wave ratio, $H V F S$ wave hepatic venous flow systolic wave, $H V F$ $D$ wave hepatic venous flow diastolic wave, $H V F A r$ hepatic venous flow during atrial reversal, $H V F S / D$ hepatic venous flow ratio of the S/D waves, TDI Et tissue Doppler imaging measurement of the tricuspid annulus velocity E wave, TDI At tissue Doppler imaging measurement of the tricuspid annulus velocity A wave, TDI Et/At tissue Doppler imaging measurement of the Et/At ratio

$3.7 \pm 0.5$ to $4.7 \pm 0.8, P<0.0001)$. The LV EDA and ESA decreased after anesthetic induction (LV EDA: $22.7 \pm 6.9$ to $16.2 \pm 5.2, P<0.0001$ and LV ESA: $12.3 \pm 6.1$ to $8.6 \pm 4.2, P<0.0001$ ) without a change in LV FAC. Both 
RV EDA and RV ESA increased (RV EDA: $13.9 \pm 3.8$ to $15.6 \pm 3.5, P=0.05$ and RV ESA: $6.9 \pm 2.3$ to $9.0 \pm 3.0$, $P=0.0003)$, whereas RV FAC decreased $(50.1 \pm 8.7$ to $42.6 \pm 13.6 \%, P=0.002)$. When compared to the examination performed the day before surgery, there were significant decreases in TMF $\mathrm{E}$ and $\mathrm{A}$ waves (TMF E: $68.3 \pm 17.0$ to $61.5 \pm 15.8, \quad P=0.0008 ;$ TMF A: $83.3 \pm 21.6$ to $55.5 \pm 18.5, P<0.0001)$, Em and Am (Em: $8.5 \pm 2.3$ to $7.0 \pm 1.5, P=0.0005$; Am: $11.7 \pm 3.2$ to $8.8 \pm 2.1, P<0.0001$ ), TTF E and A waves (TTF E: $47.2 \pm 9.8$ to $35.8 \pm 9.2, P<0.0001$; TTF A: $46.5 \pm 12.6$ to $29.5 \pm 11.9, P<0.0001)$, and Et and At (Et: $9.3 \pm 2.7$ to $5.8 \pm 1.6, \quad P<0.0001 ;$ At: $14.9 \pm 3.8$ to $8.8 \pm 2.0$, $P<0.0001)$. After induction of general anesthesia, there was an increase in the TMF E/A and TTF E/A ratios (TMF E/ A: $0.88 \pm 0.39$ to $1.36 \pm 1.28, P=0.014 ;$ TTF E/A: $1.06 \pm 0.24$ to $1.33 \pm 0.50, P=0.002)$ and the TMF Em/ Am ratio $(0.76 \pm 0.25$ to $0.84 \pm 0.28, P=0.048)$, indicating greater reductions in the atrial components of these ratios. While components of the HVF and PVF decreased, both venous flow S/D ratios increased (HVF S/D: $1.3 \pm 0.4$ to $1.6 \pm 0.5, P=0.003$; PVF S/D: $1.2 \pm 0.4$ to $1.5 \pm 0.4$, $P=0.001)$. When compared to the previous examination, the $\mathrm{LV}$ diastolic function score improved after the induction of general anesthesia (100\% of patients with an LV score $\geq 3$, pre-induction, compared to $58 \%$ of patients with an LV score $\geq 3$, post-induction; $P=0.0004$ ). No significant change in $\mathrm{RV}$ diastolic function score was observed after induction ( $19 \%$ of patients with an RV score $\geq 3$ the day before surgery; $5 \%$ of patients with an RV score $\geq 3$ after induction; $P=0.125$ ) (Table 3). Figure 3 summarizes the main findings.

\section{Patient outcomes}

In the postoperative period, there were two deaths; five patients required tracheal re-intubation for respiratory

Table 3 Left and right ventricular diastolic function

\begin{tabular}{ccccc}
\hline & Score & $\begin{array}{l}\text { Pre-induction } \\
\text { n }(\%)\end{array}$ & $\begin{array}{l}\text { Post-induction } \\
\text { n }(\%)\end{array}$ & $P$ value \\
\hline LVDD & 1 & $0(0 \%)$ & $0(0.0 \%)$ & 0.0004 \\
& 2 & $0(0 \%)$ & $20(41.7 \%)$ & \\
& 3 & $40(87.0 \%)$ & $22(45.8 \%)$ & \\
& 4 & $5(10.9 \%)$ & $5(10.4 \%)$ & \\
RVDD & 5 & $1(2.2 \%)$ & $1(2.1 \%)$ & \\
& 1 & $0(0 \%)$ & $1(2.4 \%)$ & 0.125 \\
& 2 & $30(81.1 \%)$ & $38(92.7 \%)$ & \\
& 3 & $7(18.9 \%)$ & $2(4.9 \%)$ & \\
& 4 & $0(0 \%)$ & $0(0 \%)$ & \\
\hline
\end{tabular}

$L V D D$ left ventricular diastolic dysfunction score, $R V D D$ right ventricular diastolic dysfunction score failure; three patients contracted pneumonia; two patients had pulmonary edema; two experienced a period of ventricular tachycardia; two developed acute renal failure, and none suffered from myocardial infarction. Other postoperative outcomes are summarized in Table 1. There were no differences in outcome between patients whether or not their diastolic function score improved after the induction of anesthesia.

\section{Discussion}

In patients with preoperative LV diastolic dysfunction undergoing $\mathrm{CABG}$, general anesthesia induced significant changes in cardiac dimensions and Doppler velocities. First, we observed that both left and right atria increased in size with opposite alterations in LV ventricular geometry. The RV dimensions increased, but the LV size was reduced. Second, these changes were associated with modifications in bi-ventricular filling patterns, i.e., mainly a decrease in most components of Doppler velocities. However, after general anesthesia, the E/A, Em/Am, and Et/At ratios increased, indicating greater reductions in the atrial components of these ratios. Using newer Doppler modalities, which are relatively load-independent, ${ }^{17}$ we also observed an improvement in the LV diastolic function score after the induction of general anesthesia.

These changes, along with the increased hepatic and pulmonary venous flow S/D ratio, the increased bi-atrial and RV dimensions, as well as the decreased LV size, may be explained by three mechanisms: a reduction in venous return, negative inotropic effects of general anesthesia, and the effects of positive pressure ventilation.

The change in diastolic filling pattern following induction of anesthesia is the result of many interacting factors. General anesthesia can result in decreased LV and RV preload through direct venous dilatation induced by anesthetic agents and reduced sympathetic nervous system outflow and stroke volume. These changes are consistent with the observed decrease in all flow velocities. General anesthesia may also have a negative inotropic effect, which could alter atrial systolic function ${ }^{18}$ and possibly contribute to bi-atrial dilatation. This may explain the decreased atrial contribution to ventricular diastolic filling. To support this hypothesis, Hung et al. ${ }^{19}$ showed that volume reduction using hemodialysis is not associated with a change in either TDI active atrial filling or Am. This suggests that a reduction in the relative contribution of active atrial observed in our study is not an isolated effect on preload. The possibility of altered atrial mechanical function secondary to the effect of general anesthesia must also be considered. 


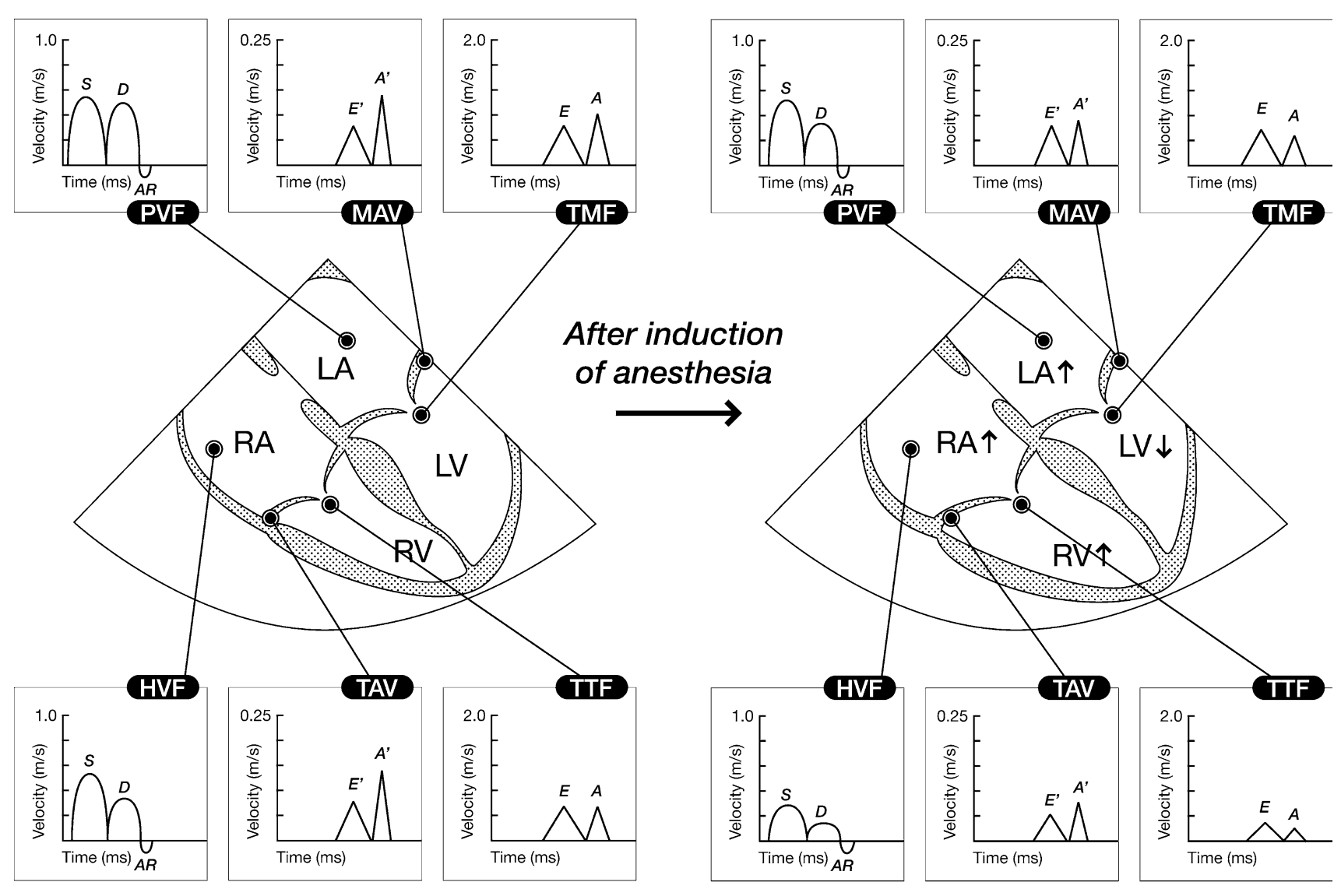

Fig. 3 Summary of the changes in cardiac dimensions and bi-ventricular filling patterns after the induction of anesthesia. TMF: transmitral flow velocity; TTF: transtricuspid flow velocity; PVF: pulmonary venous flow velocity; HVF: hepatic venous flow velocity; MAV: mitral annulus velocity; TAV: tricuspid annulus velocity. Peak early (E) and peak late (A) diastolic flow velocities

The changes in the diastolic filling pattern could also be influenced by the effects of positive pressure ventilation. An increase in intrathoracic pressure will alter both the preload and the afterload of the right ventricle. First, the increase in intrathoracic pressure will lead to a reduction in the pressure gradient for venous return through an increase in right atrial pressure. ${ }^{20}$ This could explain a reduction in velocities that would be observed in the presence of reduced venous return and, consequently, cardiac output. Second, an increase in pulmonary vascular resistance (PVR) could account for an increase in RV dimensions. Varying lung volumes exert a differential effect on intraand extra-alveolar vessels, which accounts for the unique U-shaped relationship between lung volume and PVR. The effect on PVR is minimal at functional residual capacity, whereas PVR increases as volumes approach total lung capacity and residual volume during the course of the respiratory cycle. This may be observed clinically when hyperinflation of the lungs greatly increases PVR. ${ }^{21}$ were measured for TMF and TTF. Peak systolic (S), diastolic (D), and atrial reversal (AR) flow velocities were measured for HVF and PVF. Peak early (E') and peak late (A') diastolic velocities were measured for MAV and TAV. The mean value of each velocity measurement and standard deviation is provided in Table 2

The overall influence of positive pressure ventilation on cardiac function might be summarized as a balance between an increase in $\mathrm{RV}$ afterload and a reduction of $\mathrm{RV}$ preload. The predominant effect on RV afterload is supported by the increase in RA and RV dimensions, along with a decrease in RV function. The final result of a dilated $\mathrm{RV}$ is reduced RV performance, resulting in decreased filling of the LV through reduced preload and interventricular septal dependence. ${ }^{12}$ The reduced LV filling in patients with LV diastolic dysfunction could be similar to the preload reduction maneuvers (such as the Valsalva) used in echocardiography to differentiate pseudonormal from normal diastolic function. ${ }^{11}$ Most studies examining the effects of anesthetic agents on myocardial function originate from animal and laboratory data. ${ }^{22,23}$ Other studies indicate an impairment of LV relaxation in the presence of inhalational agents in animal models. ${ }^{24-28}$ In contrast, there are limited data regarding the effect of anesthetic agents on diastolic function, ${ }^{18,29-31}$ and no study 
has evaluated the effect of induction of anesthesia in patients with known diastolic dysfunction undergoing CABG surgery.

There are several reports of adverse outcome in patients with preoperative diastolic dysfunction, ${ }^{2,3,5}$ as well as intraoperative dysfunction. ${ }^{1,4}$ Moreover, both LV and RV diastolic abnormalities were the most common echocardiographic findings in hemodynamically unstable patients after cardiac surgery. ${ }^{7}$ It is therefore relevant to evaluate diastolic function before, during, and after cardiac surgery. However, if assessed after the induction of general anesthesia, the actual incidence and severity of LV diastolic dysfunction during CABG surgery may be underestimated.

Perhaps the main limitation of this study was applying a modification of the algorithm of Khoury ${ }^{11}$ to assess diastolic function scores during changing loading conditions. Doppler measurement of diastolic function is load-dependent. ${ }^{32}$ Changes in TMF have been noted with changes in loading conditions, various heart rates, and alterations of the LV contractile state. ${ }^{32}$ Even if TDI measurements of the mitral annulus velocity are relatively load-independent, ${ }^{33}$ the measurement of Am varies depending on sample position. Therefore, it is preferable to use Em rather than the Em/Ea ratio. Moreover, it was subsequently shown that Em can be significantly reduced by a reduction in preload. ${ }^{19,34}$ Since these measurements are mainly loaddependent, it is not possible to conclude that modification of these parameters is an indicator of improved diastolic function when loading conditions are modified. The improved diastolic function score would more likely be related to a greater reduction of the atrial component of these ratios rather than to a measurable improvement of diastolic function. It is possible that the observed differences are related to different techniques, i.e., TTE in the preoperative period and TEE after the anesthetic induction. Ideally, the same method should have been used, but TTE is difficult to use in patients under anesthesia. To avoid myocardial ischemia in our patients, we did not contemplate using TEE in an awake patient before CABG. However, cross-sectional TEE measurements were shown to be equivalent to TTE measurements. ${ }^{35}$ Still, we cannot eliminate, with certainty, the possibility that the different methods of measurement may have influenced the results. Another limitation is the fact that the analysis relates to only two points in time, i.e., pre-and post-induction. However, the measurements were completed in a stable hemodynamic condition at standardized time points for each patient. Moreover, the blood pressure was comparable between the two groups at the time the echocardiographic data was obtained. These findings apply to a patient population with known diastolic dysfunction that is undergoing CABG after anesthetic induction with sufentanil and midazolam maintained with isoflurane and mechanical ventilation.

Despite certain limitations of this study design, there is evidence to support our observations that changes in Doppler velocities occurring after induction of anesthesia reflect a reduction in venous return that results in a decrease in LVEDA, left and right atrial systolic dysfunction (associated with a decreased contribution from the atrial filling to the ventricular diastolic filling), and increased PVR. The extent to which these changes reflect a transient improvement in diastolic function remains unclear. In summary, in the presence of stable blood pressure, cardiac dimensions and bi-ventricular filling patterns are altered after induction of general anesthesia and positive pressure ventilation, as reflected by increases in the dimensions of the RA, LA, and RV; a reduction in $\mathrm{LV}$ volume and a reduction in the Doppler velocities, with a greater relative decrease in the atrial component. These changes can be partly explained by a reduction in venous return, right and left atrial systolic dysfunction, and increased PVR. Although we observed an improvement in LV diastolic function score after the anesthetic induction, it is difficult to dissociate the effects on diastolic function from the loading conditions. Consequently, the extent and severity of LV diastolic dysfunction during CABG surgery may be underestimated if assessed after the induction of general anesthesia.

Acknowledgements Dr. Earl-Wynands Research Award in Cardiovascular Anesthesia 2001, Fonds de la recherche en santé du Québec (FRSQ) and the Montreal Heart Institute Foundation.

Conflict of interest None declared.

\section{References}

1. Bernard F, Denault A, Babin D, et al. Diastolic dysfunction is predictive of difficult weaning from cardiopulmonary bypass. Anesth Analg 2001; 92: 291-8.

2. Vaskelyte J, Stoskute N, Kinduris S, Ereminiene E. Coronary artery bypass grafting in patients with severe left ventricular dysfunction: predictive significance of left ventricular diastolic filling pattern. Eur J Echocardiogr 2001; 2: 62-7.

3. Liu J, Tanaka N, Murata K, et al. Prognostic value of pseudonormal and restrictive filling patterns on left ventricular remodeling and cardiac events after coronary artery bypass grafting. Am J Cardiol 2003; 91: 550-4.

4. Denault AY, Couture P, Buithieu J, et al. Left and right ventricular diastolic dysfunction as predictors of difficult separation from cardiopulmonary bypass. Can J Anesth 2006; 53: 1020-9.

5. Merello L, Riesle E, Alburquerque J, et al. Risk scores do not predict high mortality after coronary artery bypass surgery in the presence of diastolic dysfunction. Ann Thorac Surg 2008; 85: 1247-55.

6. Carricart M, Denault AY, Couture P, et al. Incidence and significance of abnormal hepatic venous Doppler flow velocities 
before cardiac surgery. J Cardiothorac Vasc Anesth 2005; 19: 751-8.

7. Costachescu T, Denault A, Guimond JG, et al. The hemodynamically unstable patient in the intensive care unit: hemodynamic vs. transesophageal echocardiographic monitoring. Crit Care Med 2002; 30: 1214-23.

8. Shi Y, Denault AY, Couture P, Butnaru A, Carrier M, Tardif JC. Biventricular diastolic filling patterns after coronary artery bypass graft surgery. J Thorac Cardiovasc Surg 2006; 131: 1080-6.

9. Couture P, Denault AY, Pellerin M, Tardif JC. Milrinone enhances systolic, but not diastolic function during coronary artery bypass grafting surgery. Can J Anesth 2007; 54: 509-22.

10. Lang RM, Bierig $M$, Devereux RB, et al. Recommendations for chamber quantification: a report from the American Society of Echocardiography's Guidelines and Standards Committee and the Chamber Quantification Writing Group, developed in conjunction with the European Association of Echocardiography, a branch of the European Society of Cardiology. J Am Soc Echocardiogr 2005; 18: 1440-63.

11. Khouri SJ, Maly GT, Suh DD, Walsh TE. A practical approach to the echocardiographic evaluation of diastolic function. J Am Soc Echocardiogr 2004; 17: 290-7.

12. Denault AY, Couture P, Buithieu J, Tardif JC. Transesophageal echocardiography multimedia manual: A perioperative transdisciplinary approach. Oxford: Marcel Dekker; 2005.

13. Klein AL, Hatle LK, Burstow DJ, et al. Comprehensive Doppler assessment of right ventricular diastolic function in cardiac amyloidosis. J Am Coll Cardiol 1990; 15: 99-108.

14. Appleton $C P$, Hatle $L K$, Popp RL. Superior vena cava and hepatic vein Doppler echocardiography in healthy adults. J Am Coll Cardiol 1987; 10: 1032-9.

15. Couture P, Denault AY, Carignan S, Boudreault D, Babin D, Ruel $M$. Intraoperative detection of segmental wall motion abnormalities with transesophageal echocardiography. Can J Anesth 1999; 46: 827-31.

16. Hache $M$, Denault A, Belisle $S$, et al. Inhaled epoprostenol (prostacyclin) and pulmonary hypertension before cardiac surgery. J Thorac Cardiovasc Surg 2003; 125: 642-9.

17. Jonassen AA, Bjornerheim R, Edvardsen T, Veel T, Kirkeboen $K A$. Effects of preload alterations on peak early diastolic mitral annulus velocities evaluated by tissue Doppler echocardiography. Eur J Anaesthesiol 2007; 24: 159-65.

18. Oxorn D, Edelist G, Harrington E, Tsang S. Echocardiographic assessment of left ventricular filling during isoflurane anaesthesia. Can J Anesth 1996; 43: 569-74.

19. Hung KC, Huang HL, Chu CM, et al. Evaluating preload dependence of a novel Doppler application in assessment of left ventricular diastolic function during hemodialysis. Am J Kidney Dis 2004; 43: 1040-6.

20. Guyton AC, Lindsey AW, Gilluly JJ. The limits of right ventricular compensation following acute increase in pulmonary circulatory resistance. Circ Res 1954; 2: 326-32.

21. Fischer $L G$, Van AH, Burkle $H$. Management of pulmonary hypertension: physiological and pharmacological considerations for anesthesiologists. Anesth Analg 2003; 96: 1603-16.
22. Pagel PS, Grossman W, Haering JM, Warltrier DC. Left ventricular diastolic function in the normal and diseased heart Perspectives for the anesthesiologist (2). Anesthesiology 1993; 79: 1104-20.

23. Pagel PS, Grossman W, Haering JM, Warltrier DC. Left ventricular diastolic function in the normal and diseased heart Perspectives for the anesthesiologist (1). Anesthesiology 1993; 79: 836-54.

24. Humphrey LS, Stinson DC, Humphrey MJ, et al. Volatile anesthetic effects on left ventricular relaxation in swine. Anesthesiology 1990; 73: 731-8.

25. Pagel PS, Schmeling WT, Kampine JP, Warltrier DC. Alteration of canine left ventricular diastolic function by intravenous anesthetics in vivo. Ketamine and propofol. Anesthesiology 1992; 76: 419-25.

26. Skeehan TM, Schuler HG, Riley JL. Comparison of the alteration of cardiac function by sevoflurane, isoflurane, and halothane in the isolated working rat heart. J Cardiothorac Vasc Anesth 1995; 9: 706-12.

27. Graham MR, Thiessen DB, Mutch WA. Isoflurane and halothane impair both systolic and diastolic function in the newborn pig. Can J Anesth 1996; 43: 495-502.

28. Graham MR, Thiessen DB, Mutch WA. Left ventricular systolic and diastolic function is unaltered during propofol infusion in newborn swine. Anesth Analg 1998; 86: 717-23.

29. Houltz E, Caidahl K, Adin C, Gustavsson T, Ricksten SE. Effects of halothane and isoflurane on left ventricular diastolic function during surgical stress in patients with coronary artery disease. Acta Anaesthesiol Scand 1997; 41: 931-8.

30. Neuhauser C, Muller M, Welters I, Scholz S, Kwapisz MM. Effect of isoflurane on echocardiographic left-ventricular relaxation indices in patients with diastolic dysfunction due to concentric hypertrophy and ischemic heart disease. J Cardiothorac Vasc Anesth 2006; 20: 509-14.

31. Miller DR, Wellwood M, Teasdale SJ, et al. Effects of anesthetic induction on myocardial function and metabolism: a comparison of fentanyl, sufentanil and alfentanil. Can J Anaesth 1988; 35: 219-33.

32. Nishimura RA, Abel MD, Hatle LK, Tajik AJ. Assessment of diastolic function of the heart background and current applications of Doppler echocardiography. Part II. Clinical studies. Mayo Clin Proc 1989; 64: 181-204.

33. Dumesnil JG, Paulin C, Pibarot P, Coulombe D, Arsenault M. Mitral annulus velocity by Doppler tissue imaging: practical implications with regard to preload alterations, sample position, and normal values. J Am Soc Echocardiogr 2002; 15: 1226-31.

34. Oguzhan A, Arinc H, Abaci A, et al. Preload dependence of Doppler tissue imaging derived indexes of left ventricular diastolic function. Echocardiography 2005; 22: 320-5.

35. Colombo PC, Municino A, Brofferio A, et al. Cross-sectional multiplane transesophageal echocardiographic measurements: comparison with standard transthoracic values obtained in the same setting. Echocardiography 2002; 19: 383-90. 